\title{
Guest Editorial: Reflections on the past, present and future of operations management
}

\author{
Robert E. Markland
}

Received: 7 July 2009 /Revised: 7 July 2009 / Accepted: 9 July 2009 / Published online: 28 July 2009

(C) Springer Science + Business Media, LLC 2009

\section{Introduction}

At any of our professional meetings it seems that one of the main topics of conversation at hallway meetings, coffee breaks, or cocktail receptions is the present state of operations management (OM) and its future. Much the same can be said about our academic institutions where such conversations often reach even into the offices of Deans, particularly as resource allocation decisions are being made. Having recently retired from a 40 year academic career (including Washington University, University of Missouri-St. Louis, Arizona State University and the University of South Carolina) I can tell you that such conversations have been prominent for a long time and will likely persist into the future. Such discussions are not only interesting, but also have value in that they help focus on what is important in achieving greater stature for our academic field.

This commentary is intended to be a reflection on my perspective on the past, present, and future of operations management based on my academic career. As I write this commentary I do so with a degree of humility in the hope that I will not appear to be a total "dinosaur". In this regard let me initially suggest that operations management encompasses a wide variety of intellectual pursuits. Thus, my biases as to what should be emphasized in OM reflect but one of these many perspectives. Additionally, I write from the viewpoint of both teaching and research since I believe that the two are inextricably intertwined.

R. E. Markland $(\bowtie)$

Moore School of Business, University of South Carolina, Columbia, SC 29208, USA

e-mail: bobbym@moore.sc.edu

\section{The past}

When I began my doctoral studies at Washington University in 1966, operations management was basically a combination of factory management and industrial engineering. Indeed, I can recall doing stopwatch time and motion studies using films of lathe and drill press operators, under the direction of Professor Powell Niland, who was Harvard trained and a wonderful teacher. Coincident at that time was the rapid development of operations research/ management science (OR/MS), which found particular applicability to OM. Advocated and given strong impetus by the famous Gordon and Howell (1959) and Pierson (1959) reports, OR/MS essentially revolutionized the field of OM. These two reports questioned the rigor of business school curricula, and suggested that a much greater quantitative and analytical emphasis was needed. Operations research/management science provided this analytical emphasis and held the promise of finding "optimal" solutions to many familiar OM problems such as production planning and scheduling, facility location, inventory control, logistics system design, and lot scheduling. In fact, I found that my doctoral studies consisted of a large number of applied mathematics, statistics, and OR/MS courses accompanied by a few traditional OM courses The new methods of analysis that were part of this academic revolution were greatly aided by the rapid development and power of digital computers. In many ways this era was the "perfect storm" for the associated rapid development and institutionalization of quantitatively oriented OM in business schools.

In my early years in academe, I taught both OR/MS and OM courses plus courses in statistics and on occasion a computer programming or information systems course. Most of my early research was done in the "living 
laboratory" of the Operations Research Department at Ralston Purina Company in St. Louis where I served as a consultant for 8 years. While at Ralston Purina we worked on a number of interesting and challenging mathematical programming, simulation, queuing and statistical analysis problems. Many of these problems involved classical OM issues such as the weekly scheduling, using linear programming, of all of Ralston Purina's animal food products or the redesign of the company's cereal products distribution system using simulation. I found myself becoming an applied OR/MS modeler and soon developed a graduate elective course in which students worked on solving real world problems using OR/MS techniques. This type of course, was, and continues to be, one of my favorite types of teaching experiences.

As we moved through the 1970s, the proliferation of the OR/MS revolution began to subside. As noted by Hayes (2008), the limitations of OR/MS in dealing with difficultto-quantify and complex strategic considerations in $\mathrm{OM}$ became apparent. Hayes also correctly observed that numerous $\mathrm{OM}$ academics began to look at supply chain operating systems and multi-plant networks as fruitful areas of research. Other OM academics began to focus on operations problems in service industries and governmental entities. Others began to explore problems related to crossfunctional and strategic issues.

Still later, OM developed a more international focus. As we observed the successes of two of our major foreign competitors, Germany and Japan, we discovered that to achieve their apparent competitive advantages they placed their highest priority on quality and continuous improvement. This led to a great increase in research oriented towards quality control and continuous improvement and in the number of cross-country comparisons and benchmarking studies. Process reengineering also came to the forefront as a research topic. In summary, as we moved through the 70s and $80 \mathrm{~s}$, OM broke out of its somewhat narrow applied OR/MS focus and developed a much broader research portfolio. The evolution of the $\mathrm{OM}$ curriculum in business schools followed in much the same manner, and in many business schools OR/MS courses were no longer taught. This resulted in OM courses becoming much less quantitatively oriented.

\section{The present}

As we examine the present state of the OM field, I believe that several trends are present. First, we are witnessing real growth of research in service operations management (SOM) and in the proliferation of service operations management courses. This is a natural outcome of the transformation of industrialized economies from a manu- facturing base to a service orientation. In a recent empirical assessment of the productivity of individuals and institutions in terms of service operations management research done by Smith et al. (2007), the authors concluded that a greater emphasis on SOM research appears to be inevitable.

Second, there has been a proliferation of research oriented towards theory building or theory testing in OM. At face value this is certainly a worthwhile undertaking and one which gives additional stature to our field. Indeed, this very journal was conceived and created as a vehicle for "advancing practice through theory". In their editorial which appeared in the first issue of Operations Management Research (2008), Meredith and McMullen provided a discussion of the creation of a new journal to meet this objective.

Many excellent papers on theory building and theory testing in OM have been written and published. In recent years I also have participated in these types of studies (Vickery et al. 2004; Smith et al. 2007). But, I am a bit concerned about how dominant this second trend has become, as it has led to the rapid expansion of survey research in OM. While there is nothing inherently wrong with survey research, I do suggest that the prevalence of survey research as a means of theory testing has perhaps led to the creation of many papers of less than satisfactory quality. As a reviewer for several OM journals, I have reviewed many papers with poor sampling designs, very low survey response rates, a lack of statistical validity and reliability, little or no consideration of non-response bias and a weak overall statistical analysis methodology. It seems to me, that in our haste to do theory building and testing in $\mathrm{OM}$ we may have come to rely on surveys too much as an expedient way to conduct such research. In summary, I'm not sure where this second trend is leading us.

\section{The future}

Now, let me spend a little time discussing what I see as the means of enhancing the viability of $\mathrm{OM}$ from both a teaching and research perspective as we move into the future. As I do so I would like to review two examples of what I believe are approaches to this enhancing process. While these examples are couched within the context of the Moore School at the University of South Carolina, I am reasonably certain that many of you are involved in similar activities.

In the late fall of 2002, my colleague, Kirk Karwan, and I were invited to serve on then South Carolina Governor Elect Mark Sanford's task force on improving the functioning of the SC Department of Motor Vehicles. At the time we became members of this task force, it was reported 
that the average waiting time for service at a typical SC Department of Motor Vehicle office was 48 min! Subsequent hard work by this task force led to a number of recommendations for improving the SC Department of Motor Vehicles, and after assuming office in 2003 Governor Sanford made major personnel changes at the SC Department of Motor Vehicles and elevated it to Cabinet level status in his administration. The newly energized SC Department of Motor Vehicles proceeded to implement many of the task force recommendations.

Additionally, I was able to use the operational environment of the SC Department of Motor Vehicles as a "living laboratory" for my graduate elective course in service operations management. Over the next 2 years we completed seven student team field studies at the SC Department of Motor Vehicles. Some of these studies used queuing or simulation models. Others involved information technology applications while some were concerned with basic service quality and service delivery issues. During the time we spent working with the SC Department of Motor Vehicles, considerable improvements in its overall operations were achieved as evidenced by the typical waiting time for service dropping to $8 \mathrm{~min}$. In summary, I believe that this was a very rewarding learning experience for my students. It certainly was an enjoyable teaching experience and provided a source for OM research also (see, Karwan and Markland 2006).

At the Moore School, University of South Carolina, the promotion of operations management as a viable and exciting career option is currently being advanced through active student participation in a wide range of field study projects. Under the able direction of Professor Sanjy Ahire, teams of four or five undergraduate or graduate students have completed field studies at major South Carolina and southeastern US companies (e.g., Sonoco Products Company, Pfizer-Capsugel Division, Westinghouse-Toshiba Nuclear Fuel Division, and Kaiser Aluminum). These studies have addressed logistics problems, supply chain issues, process management issues and a variety of other operations problems. Done within an elective course format, this project based course which offers a meaningful and challenging practical experience, has become increasingly popular. Additionally, several of the projects have involved Lean or Six Sigma process improvements and have led to "Green Belt" certification for the students involved in the projects. This type of course is available at many schools, and I contend that it is exactly what we need to be doing to advance the field of operations management and to make it more exciting and relevant for our students. Such field studies also often afford interesting research opportunities, including tangential survey research projects.
In addition to these two personal examples, I am greatly heartened by what I see as the increasing diversity of our OM journals, including this new journal: Operations Management Research. Almost every issue of one or more of our OM journals is devoted to some special topic or research area. This broadening of our field is an excellent development as it makes more prominent the importance and widespread applicability of what we do as both researchers and teachers.

\section{Conclusion}

In a recent article by Sodhi and Son (2005) it was reported that a survey of 647 job ads indicated that industry was increasingly placing a premium on hiring graduates with strong analytical skills. These analytical skills included modeling, data analysis, consulting and specific OM training. Project management, programming and basic information technology skills were also indicated as being important for employers. So, in my opinion much about OM has not changed over the past 40 years. We are still very much an applied discipline. Our ability to remain viable and relevant is dependent upon our ability to continue to offer solutions to real problems. Field research, particularly if it involves students, enhances both our teaching and research activities. Thus, I finish my career with the same emphasis that I started my career-so, you really can't teach an old dog new tricks!

\section{References}

Gordon RA, Howell JE (1959) Higher education for business. Columbia University Press, New York, NY

Hayes RH (2008) POM forum: operations management's next source of galvanizing energy? Prod Oper Manag 17:567-572

Karwan KR, Markland RE (2006) Integrating service design principles and information technology to improve delivery in public sector operations: the case of the South Carolina DMV. J Oper Manag 24:347-362

Meredith JR, McMullen PR (2008) Editorial: introducing operations management research: advancing theory through practice. Oper Manag Res 1:1-5

Pierson FC (1959) The education of American businessmen. McGraw-Hill Book, New York

Smith JS, Karwan KR, Markland RE (2007) A note on the growth of research in service operations management. Prod Oper Manag 16:780-790

Sodhi MS, Son BG (2005) What industry wants from OR grads. OR/ MS Today 32:32-38

Vickery SK, Droge C, Stank TP, Goldsby TJ, Markland RE (2004) The performance implications of media richness in a business-tobusiness service environment: direct versus indirect effects. Manag Sci 50:1106-1119 